DOI: 10.21892/978-958-5547-64-3.8

\title{
8. Acciones de política pública para la participación política y la igualdad de las mujeres en el departamento de Santander (Colombia)
}

\author{
José Darío Argüello Rueda ${ }^{1}$
}

\section{Introducción}

El Departamento de Santander (Colombia) cuenta con una población ${ }^{2}$ de 2’071.016 personas, el 50,56\% mujeres y el 49,44\% hombres (Gobernación de Santander, 2016-2019, pág. 42). Fruto de una configuración cultural histórica, la mujer ha sido infravalorada, relegada a determinadas labores u oficios domésticos. "Este proceso vino acompañado de la subvaloración de los roles y las funciones femeninas al interior de la familia, de modo que las tareas más tediosas, de menor rendimiento aparente pero de mayor obligatoriedad, cuando no de ocupaciones de esfuerzo bruto, le fueron asignadas sin ninguna valoración ni menos aún reconocimiento" (Gutiérrez, V., 1968), consolidando así una cultura machista y patriarcal ${ }^{3}$.

1 Abogado de la Universidad Santo Tomás. Magíster en Análisis Político de la Universitat Oberta de Catalunya. Doctorando en Seguridad Humana y Derecho Global de la Universitat Autònoma de Barcelona. Director del Centro de Investigaciones Sociojurídicas de la Corporación Universitaria del Caribe CECAR. .

2 Según los datos disponibles más recientes 2016), aproximaciones de población del Departamento Administrativo Nacional de Estadística y el Plan de Desarrollo del Departamento de Santander.

3 Desde esa construcción cultural, se observa que es un comportamiento común en los hombres machistas demostrar entre sus grupos la opresión que ejercen sobre las mujeres, como bien lo describe la Fundación Mujer y Futuro: "el dominio impuesto sobre la mujer es de autoridad y frente a otros hombres, en el plano de la actividad económica, el santandereano se ha caracterizado por su fuerte individualismo, con dificultades para asociarse dada su personalidad independiente" (Fundación Mujer y Futuro, 2009). Dificultades que se traducen en comportamientos machistas en la interacción con la sociedad, pero especialmente en el interior de las familias, es decir, las "conductas machistas se perpetúan con un sistema arraigado de creencias” (Cortés, 2017). 
A partir de las desigualdades enfrentadas en la región, las mujeres empezaron a participar del escenario electoral y político del Departamento, abriendo nuevos espacios para su incidencia directa4. A continuación, se observa el consolidado de mujeres electas en el departamento desde el año 2001 a 2011 , período en el que se desarrolló el agendamiento, formulación e implementación de la política pública.

Tabla 1

Santander: comparación de Participación Femenina según Instancias de Representación Política y períodos

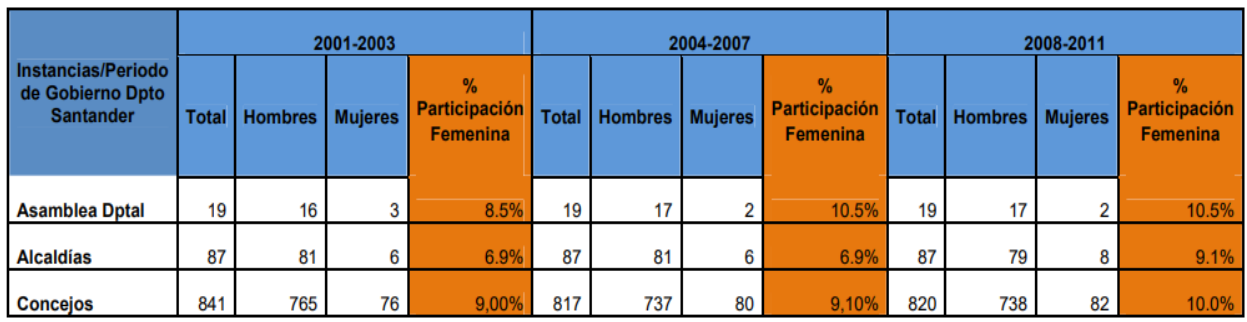

Fuente: Registraduría Nacional del Estado Civil. Tomado de Diagnóstico de Brechas de Género en Santander.

En ejecución de la Política Pública se han llevado a cabo dos contiendas electorales en los años 2011 y 2015, en las que, si bien se vio un aumento en la llegada al poder por parte de mujeres, este sigue siendo bajo en comparación con la histórica concentración del poder en los hombres. Aunque sea cierto que con el paso de los años son más las mujeres que llegan al poder, lamentablemente su participación sigue siendo muy por debajo del veinte por ciento. Por lo tanto, se presenta la siguiente evaluación de diseño del componente de participación política de la PPMEG en Santander, con el objetivo de determinar la coherencia entre las propuestas de la Política, más las necesidades que con esta se pretenden resolver.

4 Con el objetivo de hacer efectivo ese artículo de la Constitución Política de Colombia, que entre sus líneas establece que "Las autoridades garantizarán la adecuada y efectiva participación de la mujer en los niveles decisorios de la Administración Pública" (Constitución Política de Colombia, 1991.,Art. 40) y lo consagrado en el artículo 43 frente a la igualdad de derechos y oportunidades entre hombres y mujeres. 


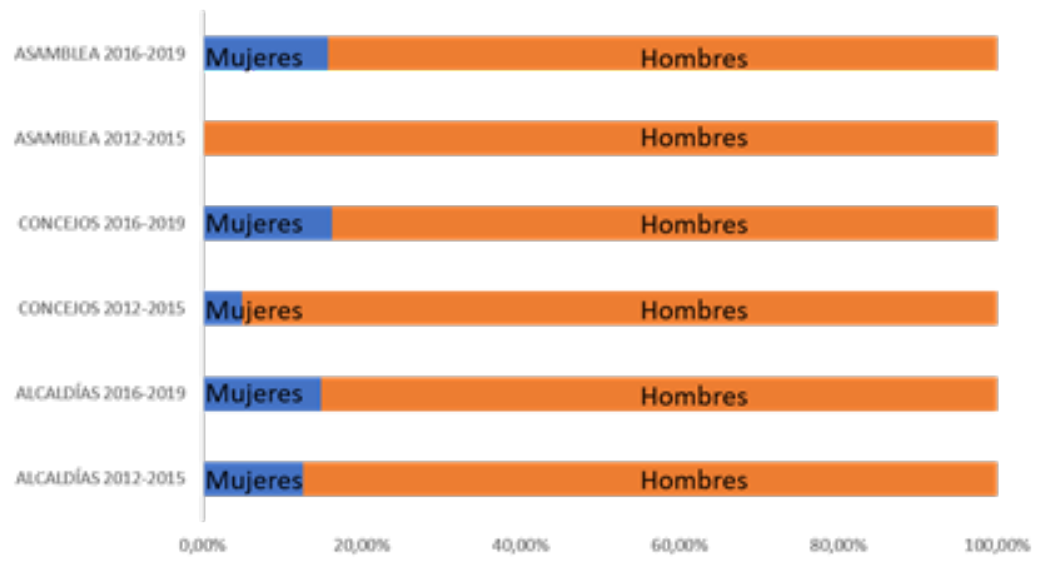

Gráfico 1. Porcentaje de mujeres electas. Períodos 2012-2019.

Fuente: Elaboración propia. Datos de la Registraduría Nacional del Estado Civil.

\section{Contexto y antecedentes de la PPMEG}

Para entender la presente investigación es necesario un acercamiento al concepto de política pública, partiendo de que esta es la respuesta de una autoridad frente a un problema público. Al respecto, las políticas públicas son para Dubnick y Bardes "acciones gubernamentales, lo que los gobiernos dicen y lo que hacen con relación a un problema o una controversia" (Dubnickm, M y Bardes, B, 1983, pág. 7). Para Kraft y Furlong son "un curso de acción o inacción gubernamental en respuesta a problemas públicos" (Kraft, M y Furlong, S, 2007, pág. 5). Según la definición de Anderson es "una orientación deliberadamente seguida por un actor o por un grupo de actores al tratar un problema o una cuestión que les concierne" (Anderson, J, 2003, pág. 3).

De esta manera, las políticas públicas ${ }^{5}$ se conciben como un instrumento planificado al servicio de la solución de problemas públicos de impacto en el interior de una comunidad. En este mismo sentido, es importante conocer en qué consisten las denominadas políticas públicas

5 Una definición completa y que involucra diferentes aspectos de las políticas públicas es la ofrecida por Ordoñez-Matamoros quien establece que: "La política pública es el conjunto de acciones implementadas en el marco de planes y programas gubernamentales diseñados por ejercicios analíticos de algún grado de formalidad, en donde el conocimiento, aunado a la voluntad política y los recursos disponibles, viabilizan el logro de objetivos sociales." (Ordóñez-Matamores, 2013, pág. 31). 
Acciones de política pública para la participación política y la igualdad de las mujeres en el departamento de Santander (Colombia)

locales o territoriales. Por ejemplo, para Romain Pasquier: "Corresponden al conjunto de las políticas públicas producidas por las autoridades infra estatales, es decir, tanto por las regiones, las ciudades y los departamentos, como por otras entidades territoriales locales. A menudo subestimadas, estas políticas públicas en realidad son centrales en el funcionamiento de las sociedades contemporáneas"”. (2016, pág. 456).

En materia de políticas públicas y género, se observa la incidencia de la mujer en las acciones del Estado, y la actuación de la administración a través de las políticas públicas, en perspectiva de género. De allí que se deben examinar "por un lado, la influencia de las intervenciones estatales sobre las mujeres y las relaciones de poder entre los sexos y, por el otro, las movilizaciones de las mujeres y de los movimientos feministas frente a esas intervenciones" (Jacquot, S y Mazur, A, 2016, pág. 460).

Así, se debe observar en doble vía en las acciones del Estado. Primero, la influencia e impacto en las mujeres; y segundo, la incidencia de estas en el diseño, implementación y ejecución de políticas. Claramente las políticas públicas pueden contar con enfoques de género, es decir, ser políticas con otros fines, pero que cuentan con un componente transversal de género, o ser políticas públicas de género "haciendo referencia a las políticas de igualdad o las feminist policies. Son políticas que tienen como principal objetivo la lucha contra las desigualdades y la promoción de la igualdad entre las mujeres y hombres" (Jacquot, S y Mazur, A, 2016, pág. 465).

En lo que respecta a la participación política ${ }^{7}$, y partiendo de que es un elemento esencial de los sistemas democráticos, se pude concluir

6 De conformidad con Pasquier estas políticas, "Están en el centro de las reflexiones sobre las nuevas formas de gobernanza territorial, es decir, el conjunto de situaciones de cooperación no ordenadas por la jerarquía que corresponden a la construcción, a la gestión o a la representación de territorios, en su entorno económico o institucional." (2016, pág. 458). Con lo anterior, se observa la clarificación teórica y conceptual de la importancia de las políticas locales para el desarrollo social. Es decir, no solo las políticas nacionales son de gran importancia, las políticas locales permiten mayor cercanía entre las instituciones, la ciudadanía, sus gobiernos y las necesidades más sentidas de sus poblaciones.

7 El concepto de participación política se puede encontrar en dos sentidos, por un lado, la participación en políticas o programas públicos "es la idea de tomar parte en el proceso de formulación, decisión e implementación de las políticas públicas" (Parry, G; Moyser, G y Day, N, 1992, pág. 16) y por otro, la visión electoral, que plantea la participación política desde la incidencia en los diferentes niveles del sistema político. Es decir que "el votante participa a través de su voto como el secretario de Estado participa en la elaboración de 
que es toda actividad de los ciudadanos que está dirigida a intervenir en la designación de los gobernantes y/o a influir en los mismos con respecto a una política y problema público (Mateos, sf). Frente a la participación política en perspectiva de género, se encuentra que existen brechas entre la igualdad formal, aquella que es establecida en tratados internacionales, por la constitución y las leyes, y la realidad material, que no es otra que la que enfrentan las mujeres en el escenario público y político ${ }^{8}$. La participación política de la mujer va más allá de la consagración de sus derechos y de la igualdad formal en disposiciones normativas. Consiste sobre todo en la garantía de la participación en condiciones de igualdad, la inclusión en los niveles decisorios del Estado y sus instituciones. Es permitir el acceso de la mujer a la gobernanza y administración del Estado, (Fernández, 1995) legitimando los postulados de democracia e igualdad con una aplicación práctica de estos en clave de género9 ${ }^{9}$.

\section{Objetivos estratégicos del componente de participación política y representación para la autonomía de la mujer de la PPMEG}

La PPMEG del Departamento de Santander se ha trazado objetivos para la materialización de los derechos de la mujer en materia de participación política $^{10}$. Sin embargo, este tipo de objetivos tienden a ser ambiguos y

una determinada política" (Verba, S y Nie, N, 1972, pág. 2).

8 Frente a esta participación, Anna Fernández manifiesta: "Se dice que la constitución de la mujer como sujeto político comienza en la Revolución francesa como consecuencia de las luchas burguesas que afirman la igualdad entre todos los seres humanos. Sin embargo, es un sujeto en construcción que todavía vive la discriminación política de forma directa a pesar de su voluntad expresada en las luchas históricas del sufragismo o el movimiento feminista de nuestros días. La historia de la política ha sido una historia de exclusiones de la mujer en cuanto a la concepción de la ciudadanía moderna. De hecho, la ciudadanía de la mujer, tan comúnmente tachada de "segunda categoría", es de tipo formal y se encuentra dentro de un sistema de poder eminentemente androcéntrico y masculinizante. Por otro lado, la supuesta igualdad formal encubre una desigualdad manifiesta por el acceso diferencial a los recursos." (1995, pág. 26).

9 A manera de observación general de la situación latinoamericana se encuentra que, según datos de la Comisión Económica para América Latina y el Caribe, para agosto de 2014 solo cinco presidentas gobernaban en estos territorios, teniendo un aumento en los últimos años en el número de legisladoras, juezas y alcaldesas, sin superar el 26\% en promedio, según las cifras del Observatorio de Igualdad de Género de la CEPAL. (CEPAL, 2014).

10 "Avanzar en la realización del derecho de las mujeres en su diversidad a la participación política, la representación y el ejercicio de su autonomía en las dimensiones políticas, 
Acciones de política pública para la participación política y la igualdad de las mujeres en el departamento de Santander (Colombia)

quedarse en una descripción de lo que se espera con la intervención. Lo que hace necesario traducirlos a elementos factibles y posibles respecto de las necesidades a las cuales responden. Para el caso concreto, tras el análisis de la investigación, se concluye que el primer objetivo estratégico real de este componente es (i) Reducir la brecha de participación política entre hombres y mujeres en el Departamento de Santander, Colombia a través del empoderamiento para el liderazgo político, social e institucional, como respuesta a la escasa participación de la mujer en las contiendas electorales como candidatas, y el bajo número que llega a ocupar cargos de elección popular. Así mismo, encontramos un segundo objetivo que es (ii) Maximizar la participación política de la mujer en condiciones de equidad e igualdad y su representación en la administración del Estado y la toma de decisiones públicas ${ }^{11}$, siendo este el fin último de las acciones contenidas en la política para el fortalecimiento de la participación de la mujer en los asuntos públicos y políticos del Departamento.

\section{Contexto del componente de participación política y representación para la autonomía de la mujer de la PPMEG}

En el año 2005 se inicia el proceso de agendamiento de la Política Pública de Mujer y Equidad de géneros del Departamento de Santander, como lo ha expuesto Graciliana Moreno Echavarría ${ }^{12}$, se debía posicionar en la agenda pública la equidad y los derechos de las mujeres. Según Moreno, entre los años 2005 a 2006, se identificó que uno de los principales problemas era la dispersión en las organizaciones de mujeres, su desarticulación. Como solución buscaron articular desde la diversidad, la pluralidad y la inclusión a los diferentes sectores políticos, sociales y religiosos, con el objetivo de generar mayor presión en las instituciones públicas frente a las necesidades de la mujer. (Moreno, 2018).

sociales, institucionales y subjetivas que concurren en la construcción de la democracia y en el fortalecimiento del Estado social de Derecho en el Departamento de Santander"(PPMEG, 2010, pág.35).

11 Estos objetivos estratégicos son una conclusión del investigador, producto de su análisis y desarrollo investigativo alrededor de la formulación e implementación de la PPMEG y su componente de participación política.

12 Graciliana Moreno Echavarría: Líder del proceso de agendamiento y formulación de la Política Pública de Mujer y Equidad de Géneros en Santander. Se ha desempeñado como asesora en asuntos de género de la Gobernación de Santander y alcaldías municipales. Docente universitaria e investigadora. 
Desde la movilización social de las mujeres en las provincias del Departamento de Santander en pro de la visibilización de sus problemáticas y necesidades, se constituyen acciones enfocadas en la agenda pública de los temas relacionados con la equidad de género ${ }^{13}$. Desde entonces, las organizaciones de mujeres dando continuidad a la labor de agendamiento, convocaron el Cabildo Departamental de Mujeres, siendo este un escenario de gran impacto e incidencia. Plataforma que permitió por primera vez que se pensara en el Departamento sobre la "pertinencia de una política pública dirigida a las mujeres y de un primer instrumento normativo a modo de ordenanza que diera un marco legal a dicho propósito" (Montero, 2011).

Desde las redes de mujeres y la Fundación Mujer y Futuro, se realizó un análisis y estudio detallado del Plan de Desarrollo del Departamento vigente en ese momento ${ }^{14}$, y a los Planes de Desarrollo de los Municipios capitales de provincias y del Área Metropolitana de Bucaramanga (capital del Departamento). En los cuales, manifiesta Moreno Echavarría, se encontró un tratamiento precario sobre los derechos de la mujer, que carecían de acciones para el empoderamiento, el crecimiento económico y contra la violencia hacia la mujer, lo que para ella se constituía en un "déficit democrático" (Moreno, 2018).

Las organizaciones de mujeres asumieron las elecciones regionales de 2007 (alcaldes y gobernadores), como una oportunidad única de visibilizar sus propuestas, hacerse escuchar y generar compromisos en materia de género y equidad. Aprovechando esa coyuntura electoral, y basándose en el reconocimiento de las experiencias del Departamento del Valle del Cauca, Antioquia y el Distrito Capital (Bogotá). Las Redes de Mujeres del Departamento de Santander, con el apoyo de la Oficina para la Coordinación de Asuntos Humanitarios de las Naciones Unidas (OCHA) plantearon la Agenda Por una Democracia Incluyente, con tres puntos prioritarios (i) Formulación de la Política Pública de Mujer y Equidad de Géneros, (ii) Crear el órgano rector (Secretaría de Mujer y

13 "Entre los años 2004-2006 nacieron, en algunas de las provincias del departamento, los primeros escenarios de articulación conocidos como Redes de Mujeres: Red Metropolitana de Mujeres, Red de Mujeres de la provincia de Vélez, Red de Mujeres del Magdalena Medio y Red de Mujeres del Nororiente colombiano." (Rodríguez, 2015).

14 Período 2004 - 2007. Hugo Heliodoro Aguilar Naranjo era el gobernador de Santander. 
Equidad de Género) y (iii) Crear el mecanismo de seguimiento y monitoreo a la política pública, Consejo Consultivo de Mujeres (Moreno, 2018). Con la cual "realizaron un ejercicio de interlocución con candidatos a concejo de los municipios del área metropolitana y Gobernación, en el interés de ratificar sus compromisos con los temas de las mujeres. Se resalta la firma del compromiso del entonces candidato a la Gobernación, quien fue electo para el período 2008-2011 $1^{15}$ (Rodríguez, 2015).

Pasando a la etapa de formulación de la Política, se contó con las Mesas Inter redes de Mujeres de Santander, a través de las cuales las organizaciones de mujeres lograron una participación estratégica de gran importancia en la formulación del Plan Departamental de Desarrollo 2008-2011. La incidencia de estos grupos de mujeres se dio en materia: (i) Participación en el proceso de empalme (entrega de cuentas), (ii) Participación en la Constituyente Social de Santander para una estrategia en la construcción colectiva y participativa del Plan Departamental de Desarrollo,(iii) Participación en el Consejo Departamental de Planeación. (Plan Departamental de Desarrollo, 2008-2011), que se constituye en un antecedente importante para la Política de equidad de género. En tanto y en cuanto este refleja el impacto y metas logradas por las organizaciones de mujeres a través de los años anteriores a su formulación, por la puesta en la agenda pública de los asuntos de género y equidad, desde un proceso realmente democrático y participativo.

En este contexto y tras la efectiva participación de la mujer en la formulación del Plan de Desarrollo, se da inicio a la construcción de la PPMEG del Departamento. En palabras de Moreno Echavarría, se desarrolló de manera participativa y concertada, en el que las mismas redes de mujeres tuvieron la oportunidad de formular el documento de política pública y proyectar la Ordenanza de la Asamblea Departamental, por la cual se adoptó la mencionada política ${ }^{16}$.

15 Es importante resaltar que el proceso de agendamiento contó con el apoyo y financiación del Instituto de la Mujer y para la Igualdad de Oportunidades del Gobierno de España, la oficina del Alto Comisionado para los Derechos Humanos, el Fondo de Desarrollo de las Naciones Unidas para la Mujer (UNIFEM) y la Deutsche Gesellschaft für Internationale Zusammenarbeit (GIZ) GmbH (Cooperación Alemana).

16 Ordenanza No. 28 de 2010. Asamblea Departamental de Santander. 
El proceso de diseño de la Política Pública de Mujer y Equidad de géneros del Departamento de Santander, bajo una metodología Bottom Up, contó con la participación significativa de la población civil, mujeres y entidades que coadyuvaron en la construcción de la política. Para su realización fueron activadas 8 Mesas Temáticas Provinciales y 6 Comités Interinstitucionales en 6 provincias del Departamento. La participación fue de 61 municipios, esto equivale al 70\% de los municipios del Departamento. Las Mesas Temáticas Provinciales contaron con una participación de 246 mujeres y 18 hombres, para un total de 264 personas, $65 \%$ de la sociedad civil, y el 35\% restante estuvo compuesto por representantes de las instituciones del Estado (PPMEG, 2010).

El componente de participación política de la PPMEG, parte de la premisa constitucional que "consagra la participación como principio y fundamento del Estado Social de Derecho, la reconoce como derecho y como deber, la erige como condición para el ejercicio de la ciudadanía y le confiere un sentido ético y político al establecer como necesarios sus nexos con la representación de los intereses de la ciudadanía". (PPMEG, 2010, p. 29).

Al momento de la formulación de la política (2010), en el Departamento de Santander la participación de las mujeres en la Asamblea Departamental, Alcaldías y Concejos Municipales durante los 10 años anteriores, tal como se puede ver en la tabla 7 , no superaba en promedio el $10.5 \%$ del total de elegidos, lo que representa un bajo porcentaje de representación femenina.

\section{Tabla 2}

Santander: Comparación de participación femenina, según instancias de representación política y períodos.

\begin{tabular}{|c|c|c|c|c|c|c|c|c|c|c|c|c|}
\hline Instancias/ & \multicolumn{4}{|c|}{ 2001-2003 } & \multicolumn{4}{|c|}{ 2004-2007 } & \multicolumn{4}{|c|}{$2008-2011$} \\
\hline $\begin{array}{c}\text { Gobierno } \\
\text { departamento } \\
\text { de Santander }\end{array}$ & Total & $\mathrm{H}$ & $\mathbf{M}$ & $\begin{array}{c}\text { \%Part- } \\
\text { Fem }\end{array}$ & Total & $\mathrm{H}$ & M & $\begin{array}{l}\text { \%Part- } \\
\text { Fem }\end{array}$ & Total & $\mathrm{H}$ & $\mathbf{M}$ & $\begin{array}{c}\text { \%Part- } \\
\text { Fem }\end{array}$ \\
\hline Asamblea Dptal. & 19 & 16 & 3 & $8.5 \%$ & 19 & 17 & 2 & $10.5 \%$ & 19 & 17 & 2 & $10.5 \%$ \\
\hline Alcaldías & 87 & 81 & 6 & $6.9 \%$ & 87 & 81 & 6 & $6.9 \%$ & 87 & 79 & 8 & $9.1 \%$ \\
\hline Concejos & 841 & 765 & 76 & $9.00 \%$ & 817 & 737 & 80 & $9.10 \%$ & 820 & 738 & 82 & $10.0 \%$ \\
\hline
\end{tabular}

Fuente: Período 1998 al 2007 Registraduría del Estado Civil. Período 2008-2011. Planes de Desarrollo Municipal recopilados por la Secretaría de Planeación Departamental - Elaborado por FMF. 
En la contienda electoral del período 2008-2011, a nivel de municipios, las mujeres alcanzaron representación en el $9.1 \%$, en las alcaldías de 8 municipios. Mientras que en los Concejos Municipales lograron 82 curules de un total de 820 . Lo que equivale al 10\%, evidenciando un leve incremento en comparación con las elecciones anteriores. El panorama por provincias respecto de la participación de la mujer en los Concejos Municipales permite evidenciar que el porcentaje más alto se encuentra ben un 14\%, correspondiente a la provincia Comunera. Así mismo dos provincias se encuentran por debajo del 10\%, como son la provincia de Guanentá con el 6\%, y, García Rovira con el 5\%.

\section{Participación de la Mujer por Provincias}

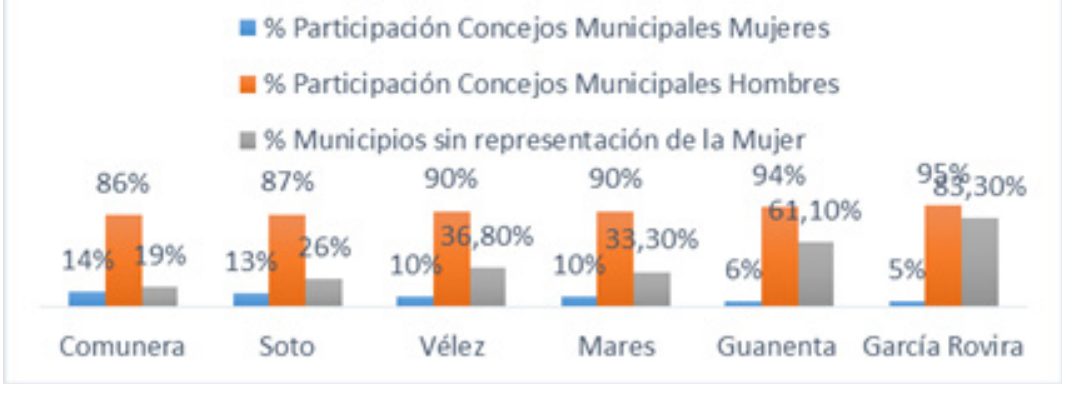

Gráfico 2. Participación de la mujer por provincias.

Fuente: Planes de Desarrollo Municipal 2008 - 2011, recopilado por la Secretaría de Planeación Departamental. Elaboración propia.

De esta manera, se demuestra que el $46 \%$ de los municipios de Santander no contaba con representación femenina en los Concejos Municipales. La provincia de García Rovira tenía la cifra más crítica en este sentido ya que contaba con el 83,30\% de sus municipios sin representación política de la mujer.

Entre los aspectos más relevantes del proceso de la Política Pública en el Departamento, cabe destacar que si bien no fue la primera política pública en materia de género y equidad en Colombia, sí es la primera política pública de su tipo en adoptarse mediante Ordenanza y no por decreto. Se presenta como la categoría normativa más alta a nivel departamental, lo que garantiza la imposibilidad de que sea derogada por futuros gobernadores, esto disminuye su vulnerabilidad ante las voluntades políticas y le otorga la 
sostenibilidad financiera en el tiempo, toda vez que contó con "la asignación en el presupuesto ordinario de cada vigencia, de una partida no inferior al $2 \%$ del valor de los ICLD apropiados para inversión y se promoverá el uso de presupuestos participativos sensibles al género" ( Ordenanza No. 028, 2010, Art. 7). Lo cual constituyó una novedad de logro en materia de políticas públicas en Colombia.

\section{Funcionamiento y responsables del Componente de Participación} Política y Representación para la Autonomía de la Mujer de la PPMEG

El Componente de Participación Política y Representación para la Autonomía de la Mujer de la PPMEG se compone de 13 acciones, las cuales se pueden clasificar en cinco subgrupos, siendo estos: (i) Formación / Educativa, (ii) Liderazgo y emprendimiento, (iii) Investigación, (iv) Institucionales y (v) Promoción. Desde el diseño de la Política se asignaron responsables y actores en los diferentes objetivos y acciones planteadas. También, en ese sentido, se plantea como estructura de operación del mencionado componente, la siguiente:

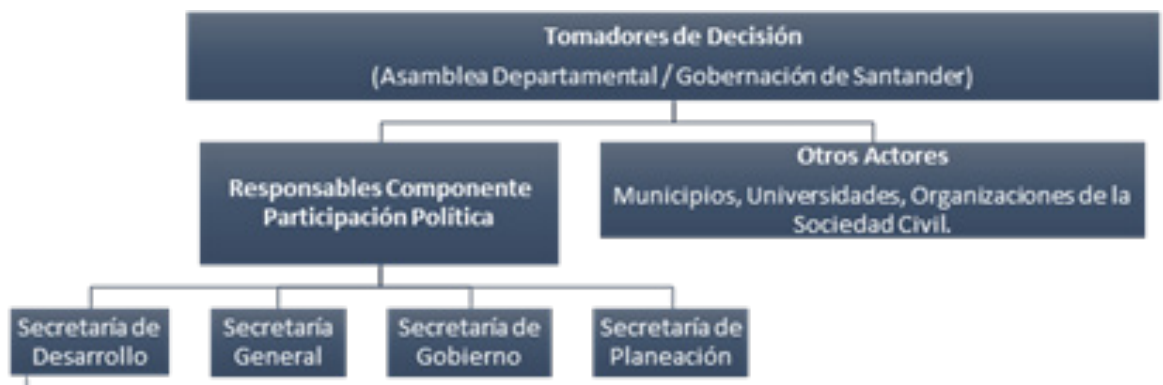

Dirección Técnica

Mujery Equidad de Género

Gráfico 3. Estructura de funcionamiento.

Fuente: elaboración propia.

\section{Teoría del cambio y modelo lógico del Componente de Participación} Política y Representación para la Autonomía de la Mujer de la PPMEG

La teoría del cambio es el modelo que permite la comprensión de las acciones de la política pública en su contexto con los recursos necesarios, los productos de las acciones, la población objetivo, la proyección de impactos y resultados esperados. De allí que se constituye en una herramienta 
trascendental para el análisis de las políticas públicas. Para el caso concreto, la teoría del cambio del Componente de Participación Política de la PPMEG, presentada a continuación, incluye los elementos ya descritos, junto con el planteamiento de hipótesis claves para el cumplimiento de lo planteado en la PPMEG, y los indicadores de medida, que inciden tanto para la adopción de las acciones plasmadas en la política, como para la evaluación de los impactos o resultados esperados. ${ }^{17}$

La teoría del cambio, junto con el modelo lógico, confirman cómo las acciones del Componente de Participación Política y Representación para la Autonomía de la Mujer de la PPMEG, responden a unos resultados esperados, que están determinados por los objetivos estratégicos del componente y, en general, aportan mucho a los fines de la PPMEG.

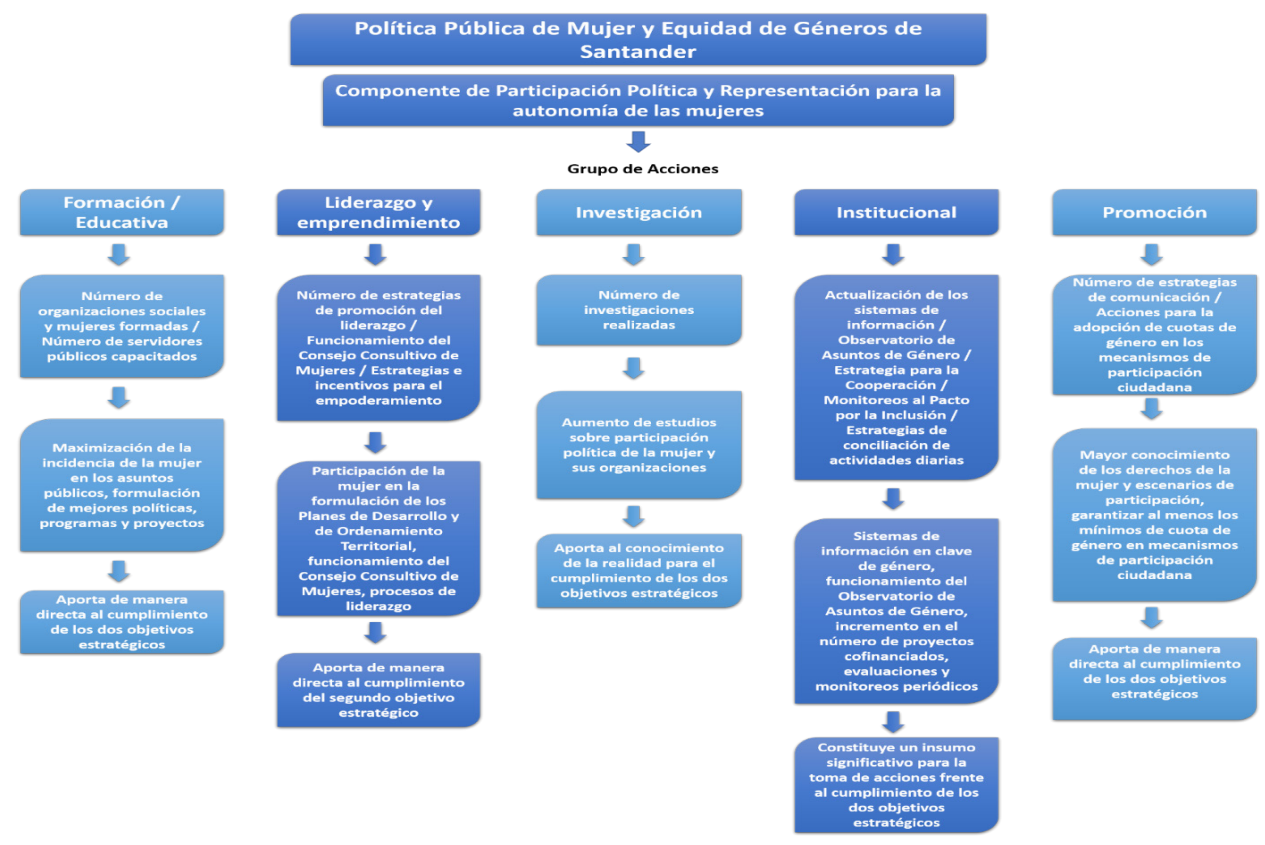

Gráfico 4. Modelo lógico.

Fuente: elaboración propia.

17 Revisar tabla de la teoría del cambio al finalizar el documento. 


\section{Análisis y evaluación de la teoría del cambio y el modelo lógico del Componente de Participación Política y Representación para la Auto- nomía de la Mujer de la PPMEG}

El componente de participación política de la PPMEG parte del reconocimiento de la "escasa, reducida o mínima representación de los intereses de las mujeres y su limitada inclusión en los escenarios y espacios de toma de decisión" (PPMEG, 2010, pág. 29) como una necesidad que se debe resolver; sin embargo, deja fuera del análisis a otras complejidades que circundan este problema público.

Al analizar las entrevistas realizadas, se observa que el problema va más allá del escaso número de mujeres ocupando cargos de elección popular, lo que podría ser más una consecuencia de otras problemáticas con un trasfondo mucho más arraigado y crítico. Como lo expresa en la entrevista Oliva Moreno"18 "La mujer no ha tomado conciencia de la participación política y de sus derechos". A esto se suma las realidades culturales del Departamento en el que predomina el machismo, y donde la ausencia de la mujer en la toma de decisiones se ha convertido en una realidad socialmente aceptada. Oliva Moreno sostiene que ser mujer hace más difícil acceder a un cargo de elección popular. Ella expone que las mismas mujeres son machistas y revela una grave situación que evidencia una tendencia de la población femenina a no apoyar a la mujer que se postula a las elecciones populares. (Moreno O, 2018). Expresa Moreno que el problema se hace más complejo, por la ausencia de condiciones reales de aplicación de las leyes y demás normatividades que garantizan la igualdad. La política, según criterio de Oliva Moreno, debe enfocarse en garantizar la participación material y efectiva de la mujer, y en eliminar la discriminación de la mujer en los escenarios de participación y liderazgo (Moreno O. , 2018).

Se hace necesario transformar aspectos culturales patriarcales que impiden la partición de la mujer en la toma de decisiones políticas. Como primera tarea se debe concientizar a la mujer de su papel y la importancia

18 Oliva Moreno Gutiérrez: Excandidata a la alcaldía de El Carmen de Chucuri, Santander. Asesora de campañas políticas. Se ha desempañado en cargos como secretaria de gobierno, secretaria de hacienda, alcaldesa encargada, entre otros, en distintos municipios del Departamento de Santander. 
política de su participación. Con esto concuerda Maritza Jiménez ${ }^{19}$, quien manifiesta que el primer obstáculo contra la participación política de la mujer es el propio machismo de las mujeres. Desde su perspectiva, entre las principales necesidades se ubica el empoderamiento de la mujer y la exaltación de sus capacidades para el liderazgo, condiciones que lleven al auto convencimiento, y se materialicen en la participación, y el liderazgo de la mujer en el ámbito tanto político como social.

Un obstáculo determinante para la incidencia de la mujer en la toma de decisiones, está relacionado con la cultura institucional y de gobierno a nivel municipal y departamental, donde la participación femenina se ha visto más como una obligación (ejemplo: la ley de cuotas de género) en vez del ejercicio de un derecho. Esto hace que "en los escenarios de toma de decisión la opinión de los hombres prime y tenga más incidencia política". (Jiménez, 2018).

Al tomar en cuenta el rol que tiene la participación para la generación de un escenario que responda a los ideales de justicia (Rodríguez $\&$ VargasChaves, 2018), y desde lo planteado en la Política Pública como acciones para la participación política de la mujer. Es necesario hacer especial énfasis en la capacitación, en la formación a través de talleres y formas diversas de transmisión de conocimiento empleando herramientas para la incidencia efectiva. Sin embargo, este tipo de acciones requieren de un cuidado especial para no caer en la celebración de eventos sin mayor trascendencia, o en el gasto de los recursos públicos, sin el cumplimiento de objetivos medibles y de generación de impactos positivos. Como lo expone Jiménez, "los recursos se van en logística y no en el impacto que se podría llevar a los municipios" (Jiménez, 2018), para quien el verdadero impacto de una acción política para el fomento de la participación, va más allá de la realización de eventos y conferencias. "Las acciones de la política deben llegar a las provincias, a la vereda, donde se pueda empezar a capacitar a las mujeres, a empoderarlas" (Jiménez, 2018). Esto representa uno de los principales retos de las acciones del componente de participación política, y que busca llegar más allá de los grandes centros urbanos o capitales provinciales. Poder impactar de manera efectiva en las mujeres rurales, y sobre todo de aquellas mujeres que son habitantes de las zonas

19 Maritza Jiménez Hernández: Gestora social 2000-2003 y 2012-2015. Actual rectora de la Institución Educativa el Centenario. Líder social y comunitaria. 
más apartadas, porque en esos lugares, más que en ninguna otra parte de Colombia, se requiere de un verdadero liderazgo social y político de las mujeres, que promueva el desarrollo de las comunidades y los territorios, desde una gestión que disminuya el machismo.

Se evidencia la necesidad de la formación y orientación específica de las mujeres para el liderazgo político. Toda vez que las mujeres en sus comunidades son líderes en otros escenarios como el religioso, social, cultural. Sin embargo, por los impedimentos ya señalados de la misma cultura, y por el escenario político propio, históricamente dominado por hombres y carente de verdaderos espacios de participación incluyente, hace que las mujeres no se atrevan en ocasiones a dar el paso necesario para pasar de un liderazgo social a un liderazgo político, que les permita llegar a cargos de elección popular, y acceder al poder para la toma de decisiones, ya que, como lo explica Jiménez, el empoderamiento de las mujeres es una salida transformadora frente a la práctica de la política tradicional. (Jiménez, 2018).

Si bien el documento de la PPMEG, en lo que respecta al componente de participación política, no elabora la lista de las necesidades o problemáticas más sentidas, como aquellas que dificultan la participación efectiva de la mujer. En todo caso, de las acciones establecidas se puede evidenciar que la falta de conocimientos, de formación para el ejercicio de sus derechos civiles y políticos, se tomó como un orientador de su posicionamiento y desempeño Político. Pese a que la política contempla, sin duda, acciones de formación de liderazgo, formulación de proyectos, administración pública, entre otras. Aunque todos estos temas están enfocados en fortalecer el papel de la mujer en el escenario público y político, todavía se carece de una estrategia que garantice la continuidad de estos procesos formativos para quienes se involucran.

Una acertada estrategia para la educación de la mujer en el liderazgo social y político, debe enfocarse en las etapas escolares. Desde la infancia y la adolescencia se requiere promover la participación igualitaria de la mujer en estos espacios, aprovechando escenarios como la Personería Escolar ${ }^{20}$

20 En todos los establecimientos educativos el personero de los estudiantes será un alumno que curse el último grado que ofrezca la institución. Este se encarga de promover el ejercicio de los deberes y derechos de los estudiantes consagrados en la Constitución Política, las leyes, los reglamentos y el Manual de Convivencia. (MINEDUCACIÓN , 2010). 
Acciones de política pública para la participación política y la igualdad de las mujeres en el departamento de Santander (Colombia)

y la Contraloría Escolar ${ }^{21}$. Los cuales son cargos de elección popular en las instituciones educativas. Estos escenarios son los primeros puntos de contacto de la mujer con el liderazgo político, que desde los colegios se empodere a la mujer para participar, se le prepare para la incidencia en los asuntos colectivos y, a su vez, se eduque a la comunidad estudiantil, quienes serán los electores del mañana, y así irse preparando para recibir mujeres empoderadas en la política. La participación igualitaria de la mujer en los espacios escolares es una oportunidad que garantiza un doble beneficio. Primero, está la transformación de la mentalidad de la mujer, en el sentido de promover su convencimiento y reconocimiento de capacidades para el liderazgo y la participación. Segundo, estaría la generación de conciencia social y cambios culturales, en cuanto a la percepción de la mujer en la política como un hecho relevante y positivo para la comunidad. Concuerda con esto Maritza Jiménez, quien en la actualidad se desempeña como Rectora de una institución educativa. Ella percibe este escenario como el ideal para "fomentar la participación de la mujer", y desde ahí promover en la mujer su capacidad para el ejercicio del poder. Como bien lo expresa la Secretaria de Educación del Departamento de Santander Andrea Aguilar22 "hacer ver atractivo para el género femenino los espacios de poder político" (Aguilar, 2018).

$\mathrm{Al}$ analizar las necesidades que busca responder el Componente de Participación Política de la PPMEG a partir de la posición de Yamile Gordillo $^{22}$, tenemos que una de las conclusiones es la de fortalecer la educación, y los espacios de formación para la mujer, tanto en materia de educación formal como de formación para el liderazgo. Con procesos formativos transformadores, enfocados en empoderar a la mujer y en brindarle herramientas suficientes y óptimas para el liderazgo activo. Así mismo, es necesario fortalecer los procesos incipientes de participación e

21 Es el educando elegido democráticamente por los demás estudiantes matriculados, para representar en la Institución Educativa el perfil de encargo académico frente al ejercicio de control social. Se encargará de velar por la promoción y fortalecimiento del control social, y fortalecimiento de control social de la gestión educativa, garantizando la transparencia, la honestidad, el compromiso, la coherencia, la solidaridad, el respeto y la responsabilidad de la institución educativa en su conjunto. (Secretaría de Educación, s.f.).

22 Balkis Yamile Gordillo Moreno: Asesora de diferentes entidades estatales en temas de políticas públicas. Candidata a magister en gobierno y políticas públicas de la Universidad Externado de Colombia. Líder social en el contexto provincial. 
incidencia de la mujer en las provincias como impulso y motivación a sus inquietudes de liderazgos, y fomento para futuras aspiraciones políticas y electorales. Ya que "la mujer en la política quiere transformar situaciones indeseadas (...) la mujer tiene una visión más social y de transformar vidas". Para lo cual se deben disipar las barreras institucionales aún existentes, como la dificultad en el acceso a los recursos para las iniciativas de las mujeres y la poca motivación y reconocimiento por su labor de liderazgo. (Gordillo, 2018).

\section{Conclusiones}

Con el análisis de lo que fue el proceso de agendamiento de la PPMEG en Santander, la construcción de la teoría del cambio y el modelo lógico del Componente de Participación Política y Representación para la Autonomía de la Mujer de la PPMEG, se obtiene una mayor comprensión de las realidades a las que las mujeres en sus territorios se enfrentan a la hora de participar en la política y asumir liderazgos. Así como de los intereses tanto de quienes promovieron la formulación de la política pública como de los tomadores de decisiones que permitieron y garantizaron las condiciones para su implementación.

Como el objetivo de este capítulo es presentar los resultados de la evaluación de diseño del componente mencionado, hay que expresar que en materia de participación de la mujer, se requiere del reconocimiento de las realidades territoriales específicas en la formulación de la política. Se evidencia una significativa caracterización de los diferentes procesos políticos y electorales, sujetos a los mecanismos de participación ciudadana en las diferentes provincias del Departamento. Allí se observa una construcción participativa del componente, y de la política que se ajusta a las realidades de la mujer en sus comunidades y territorios. En cuanto a la definición del problema por resolver con el componente de participación, el diseño de la política se queda corto en lo que respecta a su delimitación y al análisis de las múltiples causas, que sustente las acciones que se requieran implementar. Claramente se limita al reconocimiento de una realidad evidente como lo sigue siendo la escasa participación de la mujer en los cargos de elección popular. Donde para el 2010, año de adopción de la PPMEG, no superaba el 10,5\% del total de elegidos a nivel departamental. 
Acciones de política pública para la participación política y la igualdad de las mujeres en el departamento de Santander (Colombia)

Esto es la consecuencia visible de las verdaderas causas de los problemas, y de las cuales se destacan las siguientes:

4Ausencia de verdaderos espacios para la participación de la mujer, más allá de los requisitos formales que impongan las normatividades sobre cuotas y participación femenina.

WNecesidad de espacios de formación constante en materia de liderazgo y participación ciudadana con enfoque de género en las provincias, en los municipios y zonas alejadas de los centros poblados del Departamento. Uno de los principales retos para el fomento de la participación política de la mujer es llegar a las comunidades y territorios apartados, y empoderar a las mujeres como agentes para el desarrollo. Hay que destacarles y convencerlas de sus derechos y sus capacidades para que sean ellas mismas quienes promuevan sus liderazgos, y vayan ganando espacios de participación e incidencia.

Necesidad de activar procesos de transformación de la mentalidad de la mujer tanto a nivel individual como colectivo. La mujer debe modificar su imagen de estar ligada exclusivamente a las labores domésticas, de baja responsabilidad y, en general, esclava de los oficios socialmente asignados. Un verdadero proceso de empoderamiento de la mujer debe partir del propio reconocimiento de sus capacidades, de asumir sus derechos y arrogarse el liderazgo transformador de sus realidades y sus territorios.

4Necesidad de transformación cultural radical del imaginario colectivo de la sociedad santandereana. En términos generales, Santander sigue siendo culturalmente un Departamento machista, en el que, como lo evidenciaban algunas de las entrevistadas, las mujeres son vistas en ocasiones, incluso, como ciudadanas de segunda categoria. Por lo tanto, es necesario adoptar acciones encaminadas a la toma de conciencia social frente a la igualdad y equidad de género, y de las múltiples capacidades de la mujer, que la iguale a los hombres en el ejercicio de cualquier tipo de liderazgo y esencialmente el del liderazgo político. Que antes de juzgar a un candidato a un cargo de elección popular en razón de su género, se le haga por sus ideas y propuestas.

Fuente: elaboración propia.

Frente a los subgrupos en los que se clasificaron las acciones implementadas por el Componente de Participación Política de la PPMEG, concluimos lo siguiente:

(i) Formación / educativa: son acertadas las acciones adoptadas en la PPMEG en cuanto a la formación para la participación política por parte de las mujeres y sus organizaciones, y la capacitación para servidores públicos en temas de género y políticas públicas, formulación y gestión de proyectos, programas y políticas. Sin embargo, su nivel de impacto estará supeditado, entre otros factores, al alcance territorial de dichas acciones, acercando la formación a los municipios alejados de las capitales, a las zonas rurales y en las que se garantice la oportunidad de acceso a cualquier mujer del territorio departamental.

(ii) Liderazgo y emprendimiento: Con las entrevistas realizadas a las líderes regionales se encontraron ejemplos de emprendimientos sociales, económicos e industriales muy significativos desarrollados en las provincias, en las zonas rurales de los municipios. Allí se encuentra el reto de este 
tipo de acciones, ir más allá de la ciudad capital o de los grandes centros poblados y de promover el emprendimiento de la mujer en las distintas zonas del Departamento. Así mismo, promover y garantizar los espacios para el liderazgo femenino aplicando los mecanismos de participación ciudadana en todos los municipios, inculcando en la mujer su papel como agente fundamental para el desarrollo y transformación de las comunidades y territorios.

(iii) Investigación: la acción de fomento de la investigación en temas de género y participación de la mujer se encuentra bien diseñada, y para maximizar su impacto en la ejecución, se deben promover investigaciones aplicadas cuyo enfoque y metodología sea la del trabajo de campo, que permita el reconocimiento real de los procesos de participación ciudadana de la mujer, y de la experiencia de participación de ella en contiendas electorales y de los alcances en el ejercicio de cargos de elección popular.

(iv) Institucional: las acciones enfocadas hacia la institucionalidad departamental y municipal son de especial relevancia, ya que garantizan la continuidad de las acciones de la política pública, también la incidencia de la mujer en las decisiones públicas, así como la consolidación de los espacios garantes de la participación de la mujer.

(v) Promoción: las acciones de promoción de la PPMEG, de los derechos de la mujer y su participación, no pueden quedarse en buenas intenciones de visibilización de las acciones desarrolladas por los gobiernos de turno. Sobre todo se deben diseñar estratégicamente para motivar a la mujer a asumir liderazgos y roles transformadores en sus territorios, promoviendo la participación política como una forma de materializar sus derechos, y de este modo apostarle al desarrollo y la transformación de sus realidades, es decir, las de sus comunidades y del departamento.

Finalmente hay que concluir que el diseño del Componente de Participación Política y Representación para la Autonomía de la Mujer de la PPMEG, guarda coherencia entre el problema identificado y las acciones adoptadas como respuesta, toda vez que se adapta a las necesidades evidenciadas tanto en la PPMEG y sus antecedentes, como en la presente investigación.

En este sentido, la secuencia entre los recursos, las actividades, los productos y los impactos, son razonables porque guardan lógica entre 
sus interacciones, y, por ende, se encuentran debidamente sustentados, al disponer de la financiación necesaria para su ejecución y enmarcados en las posibilidades reales de materialización. Existe una adecuada lógica y congruencia entre los diferentes elementos que conforman el componente, lo que permite determinar que presenta un diseño optimo que garantiza la sostenibilidad de las acciones de la política pública en el tiempo, y que además permite prever resultados positivos, en cuanto al impacto de las acciones adoptadas, siendo estas acertadas respecto de las realidades de la participación política de la mujer en el Departamento de Santander.

NOTA: La tabla parte, de izquierda a derecha, con la descripción de las acciones que comprenden el componente de participación política de la PPMEG. Estas se encuentran clasificadas en grupos de actividades de acuerdo a sus fines o temáticas. Seguidamente se exponen los recursos necesarios para la realización de las actividades, el producto tangible o identificable de la acción, su población objetivo, finalizando con la representación de los impactos, los cuales se subdividen en corto y largo plazo, consolidando el resultado esperado de cada acción. 
Tabla 3

Teoría del cambio

\begin{tabular}{|c|c|c|c|c|c|c|c|c|}
\hline Definición & Acción de la Política Pública & $\begin{array}{c}\text { Grupo de } \\
\text { actividades }\end{array}$ & Recursos & Productos & Población & $\begin{array}{l}\text { Impacto a } \\
\text { corto plazo }\end{array}$ & $\begin{array}{l}\text { Impacto a } \\
\text { largo plazo }\end{array}$ & Resultados esperados \\
\hline \multirow[t]{2}{*}{ Descripción } & $\begin{array}{l}\text { Implementar estrategias de } \\
\text { formación política y ciudadana } \\
\text { con organizaciones sociales } \\
\text { y de mujeres en temas como } \\
\text { gestión de proyectos, régimen } \\
\text { contractual, administración } \\
\text { pública, funcionamiento del } \\
\text { Estado, derechos civiles y } \\
\text { políticos considerando los di- } \\
\text { versos enfoques poblacionales } \\
\text { diferenciales y las metodologías } \\
\text { apropiadas. }\end{array}$ & \multirow[t]{2}{*}{$\begin{array}{c}\text { Formación / } \\
\text { educativa. }\end{array}$} & \multirow{2}{*}{$\begin{array}{c}\text { Presupuesto, ca- } \\
\text { pacitadores, datos } \\
\text { sobre las organi- } \\
\text { zaciones sociales } \\
\text { y de mujeres, ma- } \\
\text { teriales didácticos } \\
\text { y tecnológicos, } \\
\text { espacios físicos } \\
\text { para la formación. }\end{array}$} & $\begin{array}{l}\text { Número de } \\
\text { organizacio- } \\
\text { nes sociales } \\
\text { y de mujeres } \\
\text { formadas. }\end{array}$ & $\begin{array}{l}\text { Organiza-cio- } \\
\text { nes sociales y } \\
\text { de mujeres. }\end{array}$ & $\begin{array}{c}\text { Mujeres } \\
\text { capacitadas } \\
\text { en asuntos } \\
\text { públicos, } \\
\text { administra- } \\
\text { ción, gobier- } \\
\text { no, derechos } \\
\text { fundamenta- } \\
\text { les, civiles y } \\
\text { políticos }\end{array}$ & $\begin{array}{l}\text { Fortaleci- } \\
\text { miento y } \\
\text { generación } \\
\text { de espacios } \\
\text { de parti- } \\
\text { cipa-ción } \\
\text { promovidos } \\
\text { por las } \\
\text { mujeres. }\end{array}$ & $\begin{array}{c}\text { Maximización de la inciden- } \\
\text { cia y participación de la mu- } \\
\text { jer y sus organizaciones en la } \\
\text { toma de decisiones públicas, } \\
\text { administración y asuntos de } \\
\text { gobierno. } \\
\text { Aumento en el número de } \\
\text { proyectos gestionados y } \\
\text { ejecutados por las organiza- } \\
\text { ciones de mujeres. } \\
\text { Incremento en las acciones } \\
\text { cívicas, sociales, judiciales, } \\
\text { administrativas y de cualquier } \\
\text { índole, para la exigencia y } \\
\text { materialización de los dere- } \\
\text { chos de la mujer. }\end{array}$ \\
\hline & $\begin{array}{l}\text { Realizar procesos de capaci- } \\
\text { tación y formación teórica, } \\
\text { metodológica y técnica con } \\
\text { servidoras y servidores públi- } \\
\text { cos en el nivel departamental } \\
\text { y municipal, sobre Políticas } \\
\text { Públicas de Género, derecho a } \\
\text { la participación y representa- } \\
\text { ción de las mujeres, y diseño, } \\
\text { formulación y puesta en mar- } \\
\text { cha de políticas, programas y } \\
\text { proyectos institucionales. }\end{array}$ & & & $\begin{array}{c}\text { Número de } \\
\text { servidores } \\
\text { públicos capa- } \\
\text { citados. }\end{array}$ & $\begin{array}{l}\text { Servidores } \\
\text { públicos a ni- } \\
\text { vel municipal } \\
\text { y depar- } \\
\text { ta-mental. }\end{array}$ & $\begin{array}{l}\text { Servidores } \\
\text { públicos } \\
\text { capacitados } \\
\text { para el forta- } \\
\text { lecimiento de } \\
\text { su gestión en } \\
\text { perspectiva } \\
\text { de género. }\end{array}$ & $\begin{array}{l}\text { Incremento } \\
\text { en la formu- } \\
\text { lación de } \\
\text { proyectos, } \\
\text { programas } \\
\text { y políti- } \\
\text { cos con } \\
\text { énfasis en la } \\
\text { equidad de } \\
\text { género. }\end{array}$ & $\begin{array}{c}\text { Formulación y ejecución } \\
\text { de más y mejores políticas, } \\
\text { programas y proyectos que } \\
\text { favorezcan la participación de } \\
\text { la mujer y su incidencia en lo } \\
\text { público y lo político. }\end{array}$ \\
\hline
\end{tabular}


Acciones de política pública para la participación política y la igualdad de las mujeres en

el departamento de Santander (Colombia)

Tabla 3

Teoría del cambio

\begin{tabular}{|c|c|c|c|c|c|c|c|c|}
\hline Definición & Acción de la Política Pública & $\begin{array}{c}\text { Grupo de } \\
\text { actividades }\end{array}$ & Recursos & Productos & Población & $\begin{array}{c}\text { Impacto a } \\
\text { corto plazo }\end{array}$ & $\begin{array}{c}\text { Impacto a } \\
\text { largo plazo }\end{array}$ & Resultados esperados \\
\hline \multirow{3}{*}{ Descripción } & $\begin{array}{l}\text { Emprender estrategias de } \\
\text { promoción de la participación, } \\
\text { incidencia y representación } \\
\text { de las organizaciones sociales } \\
\text { y de mujeres en la formula- } \\
\text { ción, ejecución, seguimiento } \\
\text { y evaluación de los Planes de } \\
\text { Desarrollo, Planes de orde- } \\
\text { namiento Territorial y de } \\
\text { Desarrollo rural. }\end{array}$ & \multirow{3}{*}{$\begin{array}{c}\text { Liderazgo y } \\
\text { emprendimien- } \\
\text { to. }\end{array}$} & \multirow{3}{*}{$\begin{array}{l}\text { Presupuesto, } \\
\text { capacitadores, } \\
\text { datos sobre las } \\
\text { organizaciones } \\
\text { sociales y de } \\
\text { mujeres, materia- } \\
\text { les didácticos y } \\
\text { tecnológicos, es- } \\
\text { pacios físicos para } \\
\text { la formación y } \\
\text { la reunión de las } \\
\text { mujeres, herra- } \\
\text { mientas técnicas } \\
\text { para el monitoreo } \\
\text { de Planes de } \\
\text { Desarrollo, Planes } \\
\text { de Ordenamien- } \\
\text { to Territorial y } \\
\text { Desarrollo Rural, } \\
\text { logística para el } \\
\text { funcionamien- } \\
\text { to del Consejo } \\
\text { Consultivo de } \\
\text { Mujeres, trans- } \\
\text { porte y logística } \\
\text { para los encuen- } \\
\text { tros de mujeres y } \\
\text { eventos. }\end{array}$} & $\begin{array}{l}\text { Número de } \\
\text { estrategias de } \\
\text { promoción de } \\
\text { liderazgo para } \\
\text { la incidencia } \\
\text { en asuntos } \\
\text { públicos. }\end{array}$ & $\begin{array}{l}\text { Organizacio- } \\
\text { nes sociales y } \\
\text { de mujeres. }\end{array}$ & $\begin{array}{l}\text { Organizacio- } \\
\text { nes sociales } \\
\text { y de mujeres } \\
\text { con herra- } \\
\text { mientas } \\
\text { cognitivas } \\
\text { para liderar } \\
\text { acciones de } \\
\text { desarrollo en } \\
\text { sus territo- } \\
\text { rios. }\end{array}$ & $\begin{array}{l}\text { Incremento } \\
\text { en la par- } \\
\text { ticipación } \\
\text { de la mujer } \\
\text { con aportes } \\
\text { para los } \\
\text { Planes de } \\
\text { Desarrollo } \\
\text { y de orde- } \\
\text { namiento } \\
\text { territorial. }\end{array}$ & $\begin{array}{c}\text { Participación activa y signifi- } \\
\text { cativa de las organizaciones } \\
\text { de mujeres en la formulación } \\
\text { de los Planes de Desarrollo, } \\
\text { Planes de Ordenamiento } \\
\text { Territorial y de Desarrollo } \\
\text { Rural. }\end{array}$ \\
\hline & $\begin{array}{l}\text { Asegurar el funcionamiento del } \\
\text { Consejo Consultivo de mujeres } \\
\text { del Departamento e impulsar } \\
\text { la creación de mecanismos de } \\
\text { interlocución y seguimiento a } \\
\text { nivel local sobre los temas de } \\
\text { mujer y equidad de géneros, } \\
\text { garantizando la efectiva partici- } \\
\text { pación de las mujeres. }\end{array}$ & & & $\begin{array}{l}\text { Cumpli- } \\
\text { miento de las } \\
\text { condiciones de } \\
\text { funcionamien- } \\
\text { to del Consejo } \\
\text { Consultivo de } \\
\text { Mujeres esta- } \\
\text { blecidos en la } \\
\text { Ordenanza No. } \\
\text { 032 de } 2009 \text {. }\end{array}$ & No aplica & $\begin{array}{c}\text { Convocar a } \\
\text { las sesiones } \\
\text { del Consejo } \\
\text { Consultivo de } \\
\text { Mujeres. }\end{array}$ & $\begin{array}{l}\text { Garan- } \\
\text { tizar las } \\
\text { condiciones } \\
\text { para que } \\
\text { el Consejo } \\
\text { Consultivo } \\
\text { de Mujeres } \\
\text { sesione de } \\
\text { manera } \\
\text { periódica. }\end{array}$ & $\begin{array}{l}\text { Pleno funcionamiento del } \\
\text { Consejo Consultivo de Muje- } \\
\text { res en los términos estable- } \\
\text { cidos por la Ordenanza No. } \\
032 \text { de } 2009 \text { de la Asamblea } \\
\text { Departamental de Santander. }\end{array}$ \\
\hline & $\begin{array}{l}\text { Diseñar e implementar } \\
\text { estrategias de fortalecimiento } \\
\text { organizativo y acompañamien- } \\
\text { to dirigido a incrementar la } \\
\text { participación y el empodera- } \\
\text { miento de las mujeres rurales } \\
\text { y urbanas, a partir de los } \\
\text { intercambios de experiencias } \\
\text { y la asignación de incentivos } \\
\text { públicos que promuevan el } \\
\text { liderazgo de las mujeres. }\end{array}$ & & & $\begin{array}{l}\text { Número de } \\
\text { estrategias para } \\
\text { la participación } \\
\text { y el empodera- } \\
\text { miento de las } \\
\text { mujeres }\end{array}$ & $\begin{array}{c}\text { Población fe- } \\
\text { menina rural } \\
\text { y urbana del } \\
\text { Departamen- } \\
\text { to. }\end{array}$ & $\begin{array}{l}\text { Mujeres capa- } \\
\text { citadas para } \\
\text { la creación de } \\
\text { organización- } \\
\text { nes y para } \\
\text { el desarrollo } \\
\text { comunitario. }\end{array}$ & $\begin{array}{l}\text { Aumen- } \\
\text { to en los } \\
\text { procesos de } \\
\text { desarrollo } \\
\text { comunitario } \\
\text { liderado por } \\
\text { mujeres. }\end{array}$ & $\begin{array}{l}\text { Incremento en el número } \\
\text { de procesos de liderazgo y } \\
\text { experiencias significativas } \\
\text { en cabeza de mujeres y sus } \\
\text { organizaciones en lo social, } \\
\text { político y económico. }\end{array}$ \\
\hline
\end{tabular}


Tabla 3

Teoría del cambio

\begin{tabular}{|c|c|c|c|c|c|c|c|c|}
\hline Definición & Acción de la Política Pública & $\begin{array}{c}\text { Grupo de } \\
\text { actividades }\end{array}$ & Recursos & Productos & Población & $\begin{array}{l}\text { Impacto a } \\
\text { corto plazo }\end{array}$ & $\begin{array}{c}\text { Impacto a } \\
\text { largo plazo }\end{array}$ & Resultados esperados \\
\hline \multirow[b]{2}{*}{ Descripción } & $\begin{array}{c}\text { Realizar estudios e investigacio- } \\
\text { nes en alianza con la academia } \\
\text { y las organizaciones sociales, } \\
\text { que permitan el conocimiento } \\
\text { de experiencias organizativas } \\
\text { de las mujeres del departamen- } \\
\text { to e identificar buenas prácticas } \\
\text { y divulgar ampliamente los } \\
\text { resultados. }\end{array}$ & $\begin{array}{l}\text { Investiga- } \\
\text { ción. }\end{array}$ & $\begin{array}{l}\text { Presupuesto, } \\
\text { investigadores, } \\
\text { poblaciones } \\
\text { de estudios o } \\
\text { muestras, eventos } \\
\text { de divulgación } \\
\text { científica, revistas } \\
\text { científicas de } \\
\text { divulgación. }\end{array}$ & $\begin{array}{l}\text { Número de } \\
\text { investigaciones } \\
\text { realizadas. }\end{array}$ & $\begin{array}{l}\text { Población del } \\
\text { Departamen- } \\
\text { to. }\end{array}$ & $\begin{array}{l}\text { Promoción } \\
\text { de la inves- } \\
\text { tigación y } \\
\text { estudios de } \\
\text { género y par- } \\
\text { ticipación po- } \\
\text { lítica, social y } \\
\text { comunitaria } \\
\text { en el Depar- } \\
\text { tamento }\end{array}$ & $\begin{array}{l}\text { Incremen- } \\
\text { to en el } \\
\text { número de } \\
\text { investiga- } \\
\text { ciones rea- } \\
\text { lizadas en } \\
\text { el Departa- } \\
\text { mento para } \\
\text { el recono- } \\
\text { cimiento } \\
\text { de las } \\
\text { realidades } \\
\text { de la parti- } \\
\text { cipación de } \\
\text { la mujer en } \\
\text { la política y } \\
\text { lo público. }\end{array}$ & $\begin{array}{l}\text { Aumento de los estudios e } \\
\text { investigaciones sobre la parti- } \\
\text { cipación y organización de la } \\
\text { mujer en el Departamento. }\end{array}$ \\
\hline & $\begin{array}{c}\text { Adecuar los sistemas de } \\
\text { información departamental y } \\
\text { municipal, promoviendo la } \\
\text { desagregación por sexo de la } \\
\text { información, incorporando } \\
\text { indicadores de género en los } \\
\text { procesos de participación } \\
\text { política y ciudadana, para } \\
\text { hacer visible la representación } \\
\text { de las mujeres en las diversas } \\
\text { instancias de participación, } \\
\text { representación, control social, } \\
\text { veeduría ciudadana y rendición } \\
\text { de cuentas. }\end{array}$ & Institucional. & $\begin{array}{l}\text { Presupuesto, } \\
\text { equipos de } \\
\text { cómputo y } \\
\text { herramientas de } \\
\text { software para la } \\
\text { adecuación de } \\
\text { los sistemas de } \\
\text { información, ins- } \\
\text { talaciones físicas } \\
\text { con dotación, } \\
\text { personal califica- } \\
\text { do, capacitadores, } \\
\text { herramientas para } \\
\text { la formulación de } \\
\text { proyectos, bases } \\
\text { de datos de orga- } \\
\text { nizaciones civiles } \\
\text { y de mujeres, } \\
\text { agencias de coo- } \\
\text { peración nacional } \\
\text { e internacional, } \\
\text { financiadores, } \\
\text { programas de } \\
\text { responsabilidad } \\
\text { social empresarial } \\
\text { afines al género. }\end{array}$ & $\begin{array}{c}\text { Actualización } \\
\text { de los sistemas } \\
\text { de información } \\
\text { del Depar- } \\
\text { tamento de } \\
\text { Santander. }\end{array}$ & No aplica. & $\begin{array}{l}\text { Generar los } \\
\text { primeros } \\
\text { cambios en } \\
\text { el recaudo } \\
\text { de informa- } \\
\text { ción en las } \\
\text { dependencias } \\
\text { departa- } \\
\text { men-tales de } \\
\text { gobierno. }\end{array}$ & $\begin{array}{c}\text { Actualizar } \\
\text { en los mu- } \\
\text { nicipios los } \\
\text { sistemas de } \\
\text { información } \\
\text { basados en } \\
\text { enfoques de } \\
\text { género. }\end{array}$ & $\begin{array}{l}\text { Sistemas de información } \\
\text { Departamental y Municipal } \\
\text { en perspectiva de género. }\end{array}$ \\
\hline
\end{tabular}


Acciones de política pública para la participación política y la igualdad de las mujeres en

el departamento de Santander (Colombia)

Tabla 3

Teoría del cambio

\begin{tabular}{|c|c|c|c|c|c|c|c|c|}
\hline Definición & Acción de la Política Pública & $\begin{array}{c}\text { Grupo de } \\
\text { actividades }\end{array}$ & Recursos & Productos & Población & $\begin{array}{c}\text { Impacto a } \\
\text { corto plazo }\end{array}$ & $\begin{array}{c}\text { Impacto a } \\
\text { largo plazo }\end{array}$ & Resultados esperados \\
\hline \multirow{4}{*}{ Descripción } & $\begin{array}{c}\text { Crear el observatorio de } \\
\text { asuntos de Género en el } \\
\text { Departamento, estableciendo } \\
\text { compromisos a nivel munici- } \\
\text { pal, a fin de hacer seguimiento } \\
\text { al cumplimiento y avances } \\
\text { de las políticas de equidad y } \\
\text { compromisos internacionales } \\
\text { de género. }\end{array}$ & & & $\begin{array}{l}\text { Observatorio } \\
\text { de Asuntos } \\
\text { de Género de } \\
\text { Santander. }\end{array}$ & No aplica. & $\begin{array}{l}\text { Reconoci- } \\
\text { miento de la } \\
\text { necesidad del } \\
\text { Observatorio } \\
\text { de Asuntos } \\
\text { de Género de } \\
\text { Santander. }\end{array}$ & $\begin{array}{l}\text { Creación } \\
\text { del Obser- } \\
\text { vato-rio de } \\
\text { Asuntos de } \\
\text { Género de } \\
\text { Santander. }\end{array}$ & $\begin{array}{c}\text { Funcionamiento del Obser- } \\
\text { vatorio de Asuntos de Género } \\
\text { de Santander. }\end{array}$ \\
\hline & $\begin{array}{l}\text { Diseñar e implementar una } \\
\text { estrategia de fortalecimiento de } \\
\text { la cooperación internacional } \\
\text { para la cofinanciación de pro- } \\
\text { gramas en equidad de género } \\
\text { en alianza con los municipios } \\
\text { y el sector privado, así como } \\
\text { para la obtención de apoyos } \\
\text { tecnológicos y la construcción } \\
\text { de presupuestos sensibles al } \\
\text { género e índices de equidad y } \\
\text { potenciación de género en el } \\
\text { Departamento y los munici- } \\
\text { pios. }\end{array}$ & & & $\begin{array}{l}\text { Estrategias } \\
\text { para la coope- } \\
\text { ración inter- } \\
\text { nacional y la } \\
\text { cofinanciación } \\
\text { de programas. }\end{array}$ & $\begin{array}{l}\text { Población fe- } \\
\text { menina rural } \\
\text { y urbana del } \\
\text { Departa-men- } \\
\text { to. }\end{array}$ & $\begin{array}{l}\text { Generación } \\
\text { de estrate- } \\
\text { gias para la } \\
\text { búsqueda de } \\
\text { cooperación } \\
\text { internacional. }\end{array}$ & $\begin{array}{c}\text { Presenta- } \\
\text { ción de pro- } \\
\text { yectos ante } \\
\text { agencias de } \\
\text { cooperación } \\
\text { nacional } \\
\text { e interna- } \\
\text { cio-nal y } \\
\text { ante el sec- } \\
\text { tor privado, } \\
\text { para la } \\
\text { cofinancia- } \\
\text { ción de } \\
\text { acciones en } \\
\text { materia de } \\
\text { género. }\end{array}$ & $\begin{array}{l}\text { Incrementó en el número de } \\
\text { proyectos cofinanciados por } \\
\text { cooperación internacional } \\
\text { para procesos de presupues- } \\
\text { tos participativos, con enfo- } \\
\text { que género a nivel municipal } \\
\text { y departamental. }\end{array}$ \\
\hline & $\begin{array}{l}\text { Hacer seguimiento y promover } \\
\text { el cumplimiento del Pacto por } \\
\text { la inclusión efectiva de las mu- } \\
\text { jeres en la política, establecido } \\
\text { por la Consejería de Equidad } \\
\text { para la mujer, y suscrito por } \\
\text { todos los poderes públicos y } \\
\text { representantes de los Partidos y } \\
\text { movimientos Políticos }\end{array}$ & & & $\begin{array}{l}\text { Número de } \\
\text { monitoreos del } \\
\text { Pacto por la In- } \\
\text { clusión efectiva } \\
\text { de las mujeres } \\
\text { en la política. }\end{array}$ & No aplica. & $\begin{array}{l}\text { Recono- } \\
\text { ci-miento de } \\
\text { las condicio- } \\
\text { nes mínimas } \\
\text { necesarias } \\
\text { para la rea- } \\
\text { lización de } \\
\text { monitoreo } \\
\text { del Pacto por } \\
\text { la Inclusión. }\end{array}$ & $\begin{array}{l}\text { Realizar los } \\
\text { primeros } \\
\text { monitoreos } \\
\text { y segui- } \\
\text { mien-tos } \\
\text { al cumpli- } \\
\text { mien- } \\
\text { to del Pacto } \\
\text { por la In- } \\
\text { clusión. }\end{array}$ & $\begin{array}{l}\text { Evaluaciones y monitoreos } \\
\text { periódicos y efectivos al Pacto } \\
\text { por la Inclusión Efectiva de } \\
\text { las Mujeres en la política del } \\
\text { Departamento de Santander. }\end{array}$ \\
\hline & $\begin{array}{l}\text { Gestionar la implementación } \\
\text { de estrategias orientadas a } \\
\text { fortalecer la infraestructura } \\
\text { social de apoyo a la familia } \\
\text { como comedores y lavande- } \\
\text { rías públicas y cuidado de la } \\
\text { infancia y la adolescencia, para } \\
\text { favorecer la conciliación entre } \\
\text { el trabajo familiar, social, polí- } \\
\text { tico y comunitario de mujeres } \\
\text { y hombres del sector urbano }\end{array}$ & & & $\begin{array}{l}\text { Número de } \\
\text { estrategias para } \\
\text { favorecer la } \\
\text { conciliación } \\
\text { entre el trabajo } \\
\text { familiar, social, } \\
\text { político y } \\
\text { comunitario. }\end{array}$ & $\begin{array}{l}\text { Población del } \\
\text { Departa-men- } \\
\text { to }\end{array}$ & $\begin{array}{l}\text { Diseño de es- } \\
\text { trategias para } \\
\text { el mejora- } \\
\text { miento de las } \\
\text { condiciones } \\
\text { cotidianas de } \\
\text { la mujer en } \\
\text { sus labores. }\end{array}$ & $\begin{array}{l}\text { Imple- } \\
\text { men-tación } \\
\text { de algunas } \\
\text { estrategias } \\
\text { encamina- } \\
\text { das a facili- } \\
\text { tar el día a } \\
\text { día laboral y } \\
\text { doméstico. }\end{array}$ & $\begin{array}{l}\text { Mejoramiento de las condi- } \\
\text { ciones cotidianas de la mujer } \\
\text { para la conciliación entre } \\
\text { las actividades domésticas, } \\
\text { sus obligaciones laborales, el } \\
\text { liderazgo político, social, cul- } \\
\text { tural, económico y cualquier } \\
\text { forma de emprendimiento. }\end{array}$ \\
\hline
\end{tabular}


Tabla 3

Teoría del cambio

\begin{tabular}{|c|c|c|c|c|c|c|c|c|}
\hline Definición & Acción de la Política Pública & $\begin{array}{c}\text { Grupo de } \\
\text { actividades }\end{array}$ & Recursos & Productos & Población & $\begin{array}{l}\text { Impacto a } \\
\text { corto plazo }\end{array}$ & $\begin{array}{l}\text { Impacto a } \\
\text { largo plazo }\end{array}$ & Resultados esperados \\
\hline Descripción & $\begin{array}{l}\text { Diseñar y poner en marcha } \\
\text { estrategias comunicativas y } \\
\text { campañas periódicas con apo- } \\
\text { yo del sector público, privado } \\
\text { y comunitario del contexto de- } \\
\text { partamental y municipal, para } \\
\text { la difusión del derecho de las } \\
\text { mujeres a la participación, la } \\
\text { representación y el ejercicio de } \\
\text { su autonomía, que incentiven a } \\
\text { la ciudadanía en general en los } \\
\text { ámbitos urbanos y rurales en } \\
\text { el reconocer del derecho de las } \\
\text { mujeres a participar en la toma } \\
\text { de decisiones. }\end{array}$ & Promoción. & $\begin{array}{l}\text { Presupues- } \\
\text { to, medios de } \\
\text { comunicación, } \\
\text { material audio- } \\
\text { visual, logística } \\
\text { para campañas } \\
\text { institucionales, } \\
\text { asesores para los } \\
\text { municipios en } \\
\text { materia de cuotas } \\
\text { y equidad de } \\
\text { género. }\end{array}$ & $\begin{array}{c}\text { Acciones para } \\
\text { la adopción } \\
\text { de cuotas de } \\
\text { género en } \\
\text { los Consejos } \\
\text { Territoriales } \\
\text { de Planeación } \\
\text { y en todos los } \\
\text { mecanismos de } \\
\text { participación } \\
\text { ciudadana } \\
\text { departamental } \\
\text { y municipal. }\end{array}$ & $\begin{array}{c}\text { Población fe- } \\
\text { menina rural } \\
\text { y urbana del } \\
\text { Departa-men- } \\
\text { to. }\end{array}$ & $\begin{array}{l}\text { Diseño de } \\
\text { estrategias de } \\
\text { comunica- } \\
\text { ción para el } \\
\text { fomento de } \\
\text { la participa- } \\
\text { ción y los } \\
\text { derechos de } \\
\text { la mujer. }\end{array}$ & $\begin{array}{l}\text { Implemen- } \\
\text { ta-ción de } \\
\text { estrategias } \\
\text { periódicas } \\
\text { para el } \\
\text { fomento de } \\
\text { la partici- } \\
\text { pa-ción y } \\
\text { los derechos } \\
\text { de la mujer. } \\
\\
\text { Imple- } \\
\text { men-tación } \\
\text { a nivel } \\
\text { municipal } \\
\text { y departa- } \\
\text { men- } \\
\text { tal de meca- } \\
\text { nismos de } \\
\text { participaci- } \\
\text { ón que } \\
\text { garanticen } \\
\text { la mínima } \\
\text { cuota legal } \\
\text { de género. }\end{array}$ & $\begin{array}{l}\text { Garantizar al menos los } \\
\text { mínimos de cuota de parti- } \\
\text { cipación de la mujer en los } \\
\text { diferentes mecanismos de } \\
\text { participación ciudadana a } \\
\text { nivel municipal y departa- } \\
\text { mental. }\end{array}$ \\
\hline
\end{tabular}

Fuente: elaboración propia. 
Acciones de política pública para la participación política y la igualdad de las mujeres en el departamento de Santander (Colombia)

\section{Referencias}

Aguilar, I. (diciembre de 2018). Entrevista educación y participación política de la mujer. (J. D. Rueda, Entrevistador)

Alarcón, Y. (2012). Comentario a la Política Pública de Equidad de Género para las mujeres. Vniversitas, 11-14. Recuperado el 13 de 06 de 2018, de http://www.scielo.org.co/scielo.php?script=sci_arttext\&pid=S0041-90602012000200001

Anderson, J. (2003). Public Policymaking: an introduction (5ta Edición ed.). Boston: Houghton Mifflin.

Asamblea Departamental de Santander. (2013). Ordenanza No. 072. Bucaramanga, Santander.

Bustelo, M. (2004). La evaluación de las políticas de género en España. Madrid: Los libros de la catarata.

Canal UDES. (15 de 10 de 2016). El machismo sigue presente en Santander según estudio realizado por el CIMEP. Recuperado el 08 de 06 de 2018, de http:/www.udes.edu.co/comunicaciones/ item/1237-el-machismo-sigue-presente-en-santander-segun-estudio-realizado-por-el-cimep.html

CEDM. (1997). Recomendación general 23, adoptada por el Comité para la Eliminación de la Discriminación contra la Mujer, $16^{\circ}$ período de sesiones, 1997, U.N. Doc. A/52/38. Human Rights Library - University of Minnessota. Recuperado el 13 de 06 de 2018, de http:// hrlibrary.umn.edu/gencomm/Sgeneral23.htm

CIMEP - UDES. (2016). El machismo sigue presente en Santander según estudio realizado por el CIMEP. Recuperado el 08 de 06 de 2018, de Canal UDES: http://www.udes.edu.co/canal-udes.html

CONPES. (1992). Política Integral para la mujer. Bogotá, Colombia: Consejo Nacional de Política Social.

CONPES. (1994). Política para el desarrollo de la mujer rural. Bogotá, Colombia: Consejo Nacional de Política Social . Obtenido de https:// colaboracion.dnp.gov.co/CDT/Conpes/Social/23.pdf

Consejería para la Equidad de la Mujer. (2003). Mujeres Constructoras de Paz y Desarrollo. Bogotá, Colombia: República de Colombia. 
Consejería Presidencial para la Equidad de la Mujer. (1999). Plan de Igualdad de Oportunidades para las Mujeres. Bogotá, Colombia: República de Colombia.

Consejo Nacional de Política Social. (1997). Avance y ajustes de la Política de Participación y Equidad para las Mujeres. Bogotá, Colombia: República de Colombia.

Consejo Nacional de Política Social. (2013). Equidad de Género para las Mujeres. Bogotá, Colombia: República de Colombia.

Constitución Política de Colombia. (1991). Bogotá, Colombia: Leyer.

Corbetta. (2003). Metodología y técnicas de investigación social. Madrid: McGraw-Hill.

Cortés, D. (26 de 11 de 2017). Conductas machistas. Opinión y Salud. Recuperado el 08 de 06 de 2018, de https://www.opinionysalud.com/ conductas-machistas-se-perpetuan-sistema-arraigado-creencias/

DANE. (2005). Censo General 2005. Obtenido de Departamento Administrativo Nacional de Estadística.

Departamento Nacional de Planeación. (1984). Política sobre el papel de la mujer en el desarrollo agropecuario. Bogotá, Colombia: Consejo Nacional de Política Social.

Díez, María A. (2004), "La evaluación basada en la teoría y su aplicación a la política regional: algunas reflexiones teóricas”, en Gestión y Análisis de Políticas Públicas, Nos. 30-31, pp. 57-70.

Dubnickm, M y Bardes, B. (1983). Thinking about Públic Policy: A problem-solving approach. New York: Wiley.

Ferrer, M. (2016). La investigación cualitativa. En R. Borge, \& M. y. Ferrer, Técnicas de Investigación Aplicadas a la Ciencia Política (pág. 45). Barcelona, España: Universitat Oberta de Catalunya.

Fundación Mujer y Futuro. (2009). Diagnóstico de Brechas de Género en Santander. Informe de Investigación, Bucaramanga, Colombia. Recuperado el 04 de junio de 2018

Gobernación de Santander. (2016-2019). Plan de Desarrollo Departamental. Gobernación de Santander, Bucaramanga, Colombia. Recuperado el 04 de junio de 2018, de http://www.santander.gov.co/images/ cooperacion/plan_de_desarollo.pdf 
Gobernación de Santander. (12 de julio de 2017). Nos une Santander. Obtenido de http://www.santander.gov.co/index.php/actualidad/ item/655-avanza-ejecucion-de-la-politica-publica-de-la-juventud

Gordillo, Y. (noviembre de 2018). Entrevista participación política de la mujer en las provincias. (J. D. Argüello, Entrevistador)

Grossman, E. (2016). Actor: El actor en el análisis de las políticas públicas. En J. J. Cuervo, Diccionario de políticas públicas (págs. 47-53). Bogotá, Colombia: Universidad Externado de Colombia.

Gutiérrez, V. (1968). Familia y cultura en Colombia. (U. Nacional, Ed.) Bogotá: Coediciones Tercer Mundo.

ICBF. (06 de 2018). Modalidad comunitaria. Recuperado el 09 de 06 de 2018, de Primera infancia: http://www.icbf.gov.co/portal/page/portal/PrimeraInfanciaICBF/Servicios/Comunitario

Ivàlua. (2009). Guía Práctica 3 Evaluación del Diseño. Barcelona, España: Institut Català d'Avaluació de Polítiques Públiques. Recuperado el 14 de 06 de 2018, de http://www.ivalua.cat/ documents/1/06_06_2017_14_08_49_Guia3_Diseno_octubre2009_revfeb2010_massa_vermella.pdf

Ivàlua. (2009). Guía práctica 3: evaluación del diseño. Barcelona: Ivàlua.

Jacquot, S y Mazur, A. (2016). Políticas Públicas y Género. En I. J.-F. Jorge, Diccionario de Políticas Públicas (págs. 460 - 469). Bogotá, Colombia: Universidad Externado de Colombia.

Jaime, F. Dufour, G. Alessandro, M y Amaya, P. (2013). Introducción al Análisis de Políticas Públicas. Buenos Aires, Argentina: Universidad Nacional Arturo Jauretche. Obtenido de https://www.unaj.edu.ar/ wp-content/uploads/2017/02/Pol\%C3\%ADticas-p\%C3\%BAblicas2013.pdf

Jefatura de Gabinete de Ministros. (2016). Manual de base para la evaluación de políticas públicas (2da Edición ed.). Buenos Aires, Argentina: Jefatura de Gabinete de Ministros de la Nación y Ministerio de Modernización. Obtenido de https://www.argentina.gob.ar/sites/default/files/modernizacion_gestion_por_resultados_manual_ base_para_la_evaluacion_de_politicas_publicas_2016.pdf

Jiménez, M. (diciembre de 2018). Entrevista mujer y participación política: el papel de la educación. (J. D. Rueda, Entrevistador) 
Kraft, M y Furlong, S. (2007). Public Polic: politics, analysis, and alternatives (2da Edición ed.). Washington D.C: CQ Press.

Ley 1475. (2011). Bogotá, Colombia: Congreso de la República de Colombia.

Ley 1761 (2015) (Art. 2). Bogotá D.C. : República de Colombia.

Ley 581. (2000). Ley de cuotas. Bogotá, Colombia: Congreso de la República de Colombia. Recuperado el 13 de 06 de 2018, de http://www. alcaldiabogota.gov.co/sisjur/normas/Normal.jsp?i=5367

Mateos, A. (2019). Ciudadanos y participación política. USAL. https://campus.usal.es/ dpublico/areacp/materiales/ciudadanosyparticipacion. pdf. consultado el 14/01/2019.

MINEDUCACIÓN. (17 de 03 de 2010). Ministerio de Educación Nacional de Colombia. Obtenido de Al día con las noticias: https://www.mineducacion.gov.co/observatorio/1722/article-220387.html

Montero, L. y. (2011). Incidencia Política de las mujeres y transparencia en la coyuntura electoral 2011. Informe de investigación.

Montoya, A. (2009). Recorrido por las políticas públicas de Equidad de Género en Colombia y Aproximación a la experiencia de participación femenina con miras a la nueva construcción de escenarios locales. Estudios de Derecho, 147.

Moreno, G. (octubre de 2018). Entrevista Dra. Graciliana Moreno. Proceso de agendamiento y formulación de la Política Pública de Mujer y Equidad de Géneros de Santander. (Y. Gordillo, Entrevistador)

Moreno, O. (diciembre de 2018). Entrevista sobre participación política de la mujer en Santander. (J. D. Argüello, Entrevistador)

OCDE. (2002). Glosario de términos sobre evaluación y gestión de la Organización para la Cooperación y el Desarrollo Económicos. París, Francia: OCDE.

OEA. (1969). Convención Americana sobre Derechos Humanos. San José de Costa Rica: OEA. Recuperado el 13 de 06 de 2018, de https:// www.oas.org/dil/esp/tratados_b-32_convencion_americana_sobre_derechos_humanos.htm

ONU. (1966). Pacto Internacional de Derechos Civiles y Políticos. Washington D.C: OHCHR. Recuperado el 13 de 06 de 2018, de https:// www.ohchr.org/SP/ProfessionalInterest/Pages/CCPR.aspx 
Ordóñez-Matamoros, G. (2013). Manual de análisis y diseño de políticas públicas. Bogotá, Colombia: Universidad Externado de Colombia.

Osuna y Márquez. (s.f.).

Osuna, J y Márquez, C. (2000). Guía para la evaluación de Políticas Públicas. Sevilla: Instituto de Desarrollo Regional.

Parry, G; Moyser, G y Day, N. (1992). Political Participation and democracy in Britain. Cambridge: Cambridge University Press.

Pasquier, R. (2016). Políticas Locales. En I. J.-F. Jorge, Diccionario de Políticas Públicas (págs. 456-460). Bogotá, Colombia: Universidad Externado de Colombia.

Peláez, M. (2001). La Política de Género en el Estado Colombiano: Un camino de conquistas sociales. Rio de Janeiro, Brasil: Fundación Osvaldo Cruz-Fiocruz. Recuperado el 13 de 06 de 2018, de http:// www.bdigital.unal.edu.co/47458/1/lapol\%C3\%ADticadeg\%C3\%A9neroenelestadocolombiano.pdf

Plan Departamental de Desarrollo. (2008-2011). Plan Departamental de Desarrollo. Bucaramanga: Gobernación de Santander.

Rodríguez, J. (2015). El movimiento de mujeres y su incidencia en la formulación e implementación de la política pública de la mujer y equidad de Géneros en Santander, Colombia, 2007-2014. Reflexión Política, 162-176.

Rodríguez, G. A., \& Vargas-Chaves, I. (2018). Participation in Environmental Decision Making as an Imperative for Democracy and Environmental Justice in Colombia. Mediterranean Journal of Social Sciences, 9(6), 145-155.

Steve, J. (2016). Evaluación. En I. J.-F. Jorge, Diccionario de Políticas Públicas (págs. 285 - 293). Bogotá, Colombia: Universidad Externado de Colombia.

Secretaría de Educación. (s.f.). Metaportal. Obtenido de Contralor estudiantil - participar es tu derecho: http://mp.antioquiatic.edu.co/ Contralor-estudiantil/\%C2\%BFQue-es-un-contralor-estudiantil/

Uriarte, E. (2002). Introduction to Political Science: Politics in democratic societies. Madrid: Tecnos.

Verba, S y Nie, N. (1972). Participation in America: Political democracy and social equality. Chicago: The University of Chicago Press. 
José Darío Argüello Rueda

WEISS, C. H. Evaluation. 2. ${ }^{a}$ ed. Upper Saddle River, NJ: Prentice Hall, 1998. 
